find, a universal mechanism for the seasonal photoperiodic clock. This may be so, but it is difficult at the moment to equate data such as those of Lees-for the photoperiodic control of polymorphism in the aphid Megoura -with a circadian hypothesis. It is just possible that there are two or more mechanisms for the measurement of the critical day length (or night length), and the similarities between them are merely attributable to the fact that all organisms have evolved in an environment with a $24 \mathrm{~h}$ periodicity of light and dark.

The entrainment of circadian rhythms and the induction of diapause by thermoperiods are discussed in the fourth and seventh chapters, but the subject of temperature "shocks" is ignored. Chilling for short periods in the light or the dark, especially, is known to cause significant reversals of photoperiodic effect in plants and insects, and is also known to cause phase perturbation of circadian rhythms.

In the preface the author states that the presentation has been adopted so that the volume might be a useful reference for the student as well as the specialist. In my opinion this has been accomplished, and the book forms a welcome addition to the literature on photoperiodism.

D. S. SAUNDERS

\section{HISTORY OF SALMON}

\section{The Atlantic Salmon}

A Vanishing Species? By Anthony Netboy. Pp. $457+$ 24 plates. (London : Faber and F'aber, Ltd., 1968.) 70s. net.

THIs book is a history of the salmon populations of the countries bordering the North Atlantic Ocean. It is written for the general public and, in spite of a few misprints and inaccuracies, it is a scholarly account which should be of great value to all interested in the rational exploitation of natural resources.

Twelve chapters form the bulk of the book and each is a detailed account of events in one country (except for two chapters on England and Wales together). After a general introduction to the country and a description of its salmon rivers, there is an account of the changes in the salmon populations together with probable causes. The chapters end with reviews of the present situation and prognoses for the future. Mr Netboy begins his survey with Spain and works north along the European coast, then from Norway to the British Isles and thence to USA and Canada, and finally to Greenland and Iceland.

This treatment emphasizes the similarity of events in different countries. Early records show a great abundance of salmon in all suitable rivers and these were exploited only to a limited extent by the local people for their own use. The industrial revolution followed different patterns in different countries but always with deleterious effects on salmon stocks from one or more of the following causes - damming of rivers to give water power; deforestation leading to silting of spawning grounds; water pollution killing young and old fish. With improved transport, salmon were despatched to distant markets and overfishing also became a problem. Thus salmon, once abundant, became first rare and then non-existent in many rivers. A new threat since 1960 has been the fishing for salmon in the sea off Greenland and elsewhere.

The clash between industry and fisheries was generally won by industry, although anti-pollution laws existed in Ireland in 1466 and the importance of allowing some free passage upstream was recognized in Magna Carta. When salmon angling developed as a sport, there appeared a powerful new pressure group working for preservation and reinstatement of salmon rivers. The dangers to stocks during their freshwater life are now widely appre. ciated and research has led to interesting developments such as large-scale artificial smolt-rearing in Sweden.

The book includes 24 tables, many maps and diagrams, many interesting photographs, a bibliography of 17 pages and an index. Mr Netboy has travelled widely and has consulted the principal experts of many countries. He has brought together an impressive array of statistics and historical evidence. He sums up the story so far: "civilization and salmon do not mix well unless extraordinary precautions are taken to protect their habitat". We must hope that modern civilization is sufficiently enlightened for this excellent food fish to continue to survive.

M. E. VARLEY

\section{BUTTERFLY BLUES}

\section{The Complete British Butterflies in Colour}

Illustrations by E. Mansell. Text by L. Hugh Newman. Pp. 144 (62 plates). (London: Ebury Press and Michael Joseph, 1968.) 35s.

The blurb's claim that this book is "beautiful and meticulously illustrated" ranks as hyperbole rather than untruth; the further assertion that the text is "informative" can happily be described as pleonastic. This is primarily a picture book which illustrates the butterflies native and immigrant to the British Isles. Each species is given a full page plate, showing its immature and adult forms, and the foodplant; the natural history is briefly described on the facing page.

The illustrations are certainly attractive, but they are not entirely faithful to their originals. The matt paper has robbed them of much of their brightness, as may be seen by comparing the dustjacket illustration to that in the text. The colours are too drab, and many are inaccurate in hue as well as in intensity. The Fritillaries and the Blues are the most serious casualties; the Adonis Blue, for example, has in nature a startling azure iridescence, admittedly difficult to capture in print, of which the blotched subfusc offered here is but a travesty. Nor have the subtle browns of the Skippers and Hairstreaks been accurately reproduced.

It would be unjust, however, to expect complete tonal accuracy in a book the price of which is as modest as is this one. Some of the butterflies are drawn larger than the natural size they are stated to be, and in several plates the printer has aligned the female sex symbol according to his whim instead of to the vertical. These are but minor blemishes in illustrations which are otherwise well composed and well executed.

The introduction describes the natural history of butterflies eloquently but briefly. No discussion is given on the remarkable migratory habits of butterflies, which in two species at least have recently been shown to be governed by sensitivity to Sun orientation and photoperiod $^{1}$. Nor is any mention made of pheromones, the importance of which in insect behaviour has become increasingly obvious.

NICHOLAS WADE

${ }^{2}$ Baker, R. R., Phil. Trans. Roy. Soc., B, 253, 309 (1968).

\section{OBITUARIES}

\section{Professor J. W. Munro}

James Watson Munro, Emeritus Professor of Zoology and Applied Entomology, London (Imperiail College), died at the age of 79 on March 13. He had made a fundamental contribution to the developmeni of entomology in Britain, not least in persuading the Univer- 
sity of London that both taxonomy and the more practical side of entomology were subjects worthy of study at university level. Moreover, by developing during his career two different field stations, he showed the important part such institutions can play in university teaching, at least in subjects such as entomology.

Munro took his degree in zoology at the University of Edinburgh and then studied forestry at Aberdeen and at Tharandt, in Germany, under Escherich. Soon after his return to England his career was interrupted by the First World War and after a period of service in France he was withdrawn to work at Cambridge with Nuttall and Bacot on the problems of lice and scabies. About the latter, in particular, he made a valuable discoverynamely, that the main centre of itching was some distance away from the area where the mites were most numerous.

After the war, he returned to forestry. The Forestry Commission had just been set up to remedy a national deficiency which the war had brought to light. Munro wrote to the Commission proposing a programme of forest entomology which to a large extent it adopted, employing him to put it into effect. This gave him not only $a$ wide knowledge of practical problems all over Britain but also taught him some lessons in dealing with administrators and government servants. Part of his work was done at Kew and here he met the late Sir John Fryer and formed a friendship which was later fruitful when Fryer was at the Ministry of Agriculture and the Agricultural Research Council (ARC).

Munro devised the first entomological programme for the Forest Products Research Laboratory and his career in the subject seemed well launched when he was appointed to the Imperial Forestry Institute at Oxford. However, the subject did not develop there as he had hoped and he soon transferred to the Imperial College as assistant professor of entomology. Here he not only resuscitated what was a moribund department but as a substitute for the forests began the study of insect pests of stored foods in the London docks. Some of the insects could best be controlled by fumigation with various gases, but experi. ments with these were difficult to do in South Kensington. Munro was able to obtain a grant from the Empire Marketing Board to set up a field station at Slough where such experiments were possible. These experiments not only led to the development of a scientific basis for the whole subject of fumigation, previously entirely empirical and often ineffective, but also enabled a revolution to be made in the teaching of entomology at the college, with a much greater emphasis on field work and on the study of the live insect.

The work on "stored products insects" continued up to 1939 and, just before the outbreak of the Second World War, Munro had persuaded the Department of Scientific and Industrial Research (DSIR) that there was a serious practical problem which fell within its province. A system of inspection, backed by laboratory research, was set up and later taken over by the Ministry of Food and the DSIR, Munro becoming their consultant. However, in the latter part of the war he became interested in problems of medical entomology, particularly the practical control of malaria-carrying mosquitoes in jungle warfare.

In 1930 Munro had been appointed professor of entomology at Imperial College, and in 1934, when MacBride retired, the zoology and entomology departments were combined and he was appointed professor of zoology and applied entomology. After the war the college field station remained in the hands of the DSIR (now of the ARC) and Munro had not only to build up a very depleted department but to find a new field station, at a time when it was difficult to get building licences. $\mathrm{He}$ found a suitable site and a building capable of adaptation at Silwood Park, near Ascot, and, until his retirement in 1953, most of his energies, so far as he was not doing valuable work on a number of official committees, were devoted to developing Silwood so that the very necessary liaison between applied entomology and ecology would find an ideal site. Munro was prepared to examine any problem from every side and call on more than one scientific discipline, but he had an uncanny knack of finding out the most rewarding approach and, after the initial survey, concentrating on the sort of work which was most needed. It was this that made him a great and successful entomologist.

\section{Professor L. Infeld}

Lwopold INFELd died on January 15, 1968, in Warsaw. With his death, Poland lost her most distinguished theoretical physicist and the world lost a courageous and wise man.

Infeld was born in Cracow on August 20, 1898. $\mathrm{He}$ attended school there and later the Jagiellonian University where he received his doctorate in 1921. After several years of high school teaching, he worked at the University of Lwow from 1929 to 1936 . During a short visit to Leipzig, Infeld and van der Waerden wrote an important paper on the generalization of the spinor ealculus and of Dirac's equation to general relativity theory. In 1934, Infeld was awarded a Rockefeller Fellowship to work at the University of Cambridge. There he collaborated with Max Born on what is now known as the Born--Infeld theory. It was an attempt to explain the existence of elementary charged particles in terms of well behaved solutions of non-linear equations for the electromagnetic field.

In 1936 Infeld accepted a research appointment at the Institute for Advanced Study in Princeton. He worked with Albert Einstein and Banesh Hoffmann on the equations of motion in general relativity, a problem which occupied his main research interest for the rest of his life. The work showed that Einstein's theory of gravitation has a unique feature, that the field laws alone determine the motion of particles and that no independent laws of motion are needed. This beautiful result is intimately connected with the non-linearity of the gravitational field equations. It should play an important part in the future development of the whole of theoretical physics. The work also gave the first satisfactory description of the motion of several particles in gravitational interaction, such as the relativistic motion of a double star. In 1960 , Infeld and his former student Jerzy Plebanski published a treatise on motion and relativity.

After two years at Princeton, Infeld accepted a professorship in the University of Toronto where he stayed until 1950. At that time he returned to Warsaw and established a new research centre in theoretical physics. Many of his Canadian and Polish research students now have professorships at universities on the North American continent and in Poland. He received many scientific honours. He was elected to the Royal Society of Canada and to the scientific academies of Poland, Hungary and Berlin. Since 1953, he has been a member of the Presidium of the Polish Academy of Sciences.

Infeld was the author of several books. With Albert Einstein he wrote The Evolution of Physics, an exposition of modern scientific ideas for the layman. He also wrote a book on Einstein, two autobiographical volumes and a novel on the life of Evariste Galois.

Leopold Infeld was a remarkable man. He had a great zest for life and a great concern for human beings. He believed that intellectuals should speak out on human conditions and he always did so himself, with a simple elarity which was convincing and effective. $\mathrm{He}$ was particularly concerned with the great danger of our age, the annihilation of life on our planet by nuclear weapons. He was one of the original signatories of the EinsteinRussell letter of 1955. He helped organize the Pugwash conferences which brought together scientists from the East and West. 